\title{
Del PFC a hoy
}

Gómez Javaloyes, María

Universidad de Alicante, Departamento de Expresión Gráfica y Cartografía, Escuela Politécnica Superior (Arquitectura), Alicante, España.

maria.javaloyes@gmail.com

PROYECTO FIN DE CARRERA

Del PFC a hoy. 


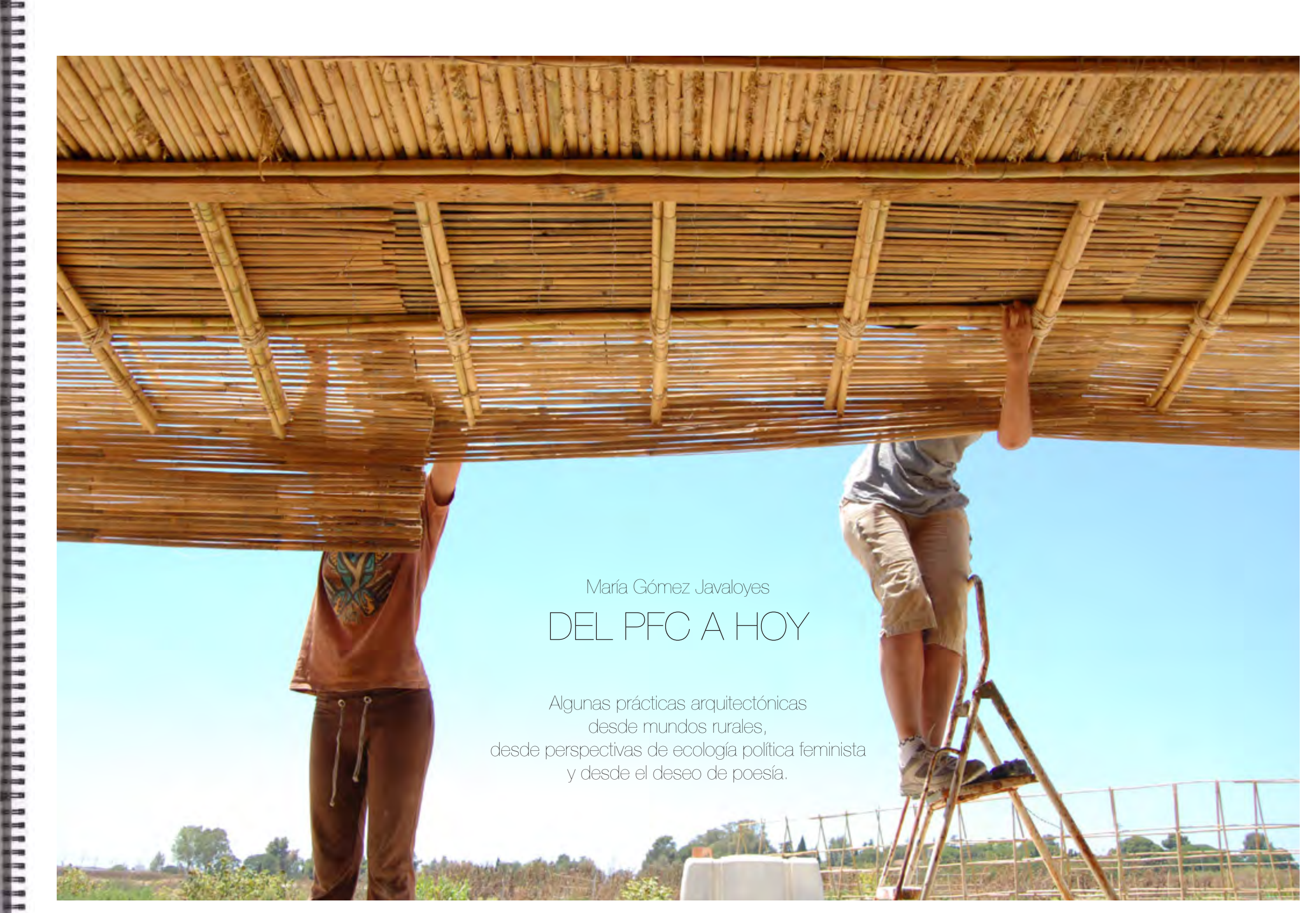




\section{DESDE LOS BORDES}

La vida no empieza en el Proyecto Final de Carrera, de arquitectura o de cualquier otra disciplina, porque antes, como estudiantes, hay vida y puede ser muy intensa. Pero desde luego un PFC puede ser un momento clave en el desarrollo posterior de la profesión. A mi debió pasarme eso.

En las siguientes páginas extraigo partes del PFC que realicé hace cinco años y trazo conexiones con algunos de los trabajos, de las formas de ser arquitecta y de habitar territorios, que he vivido posteriormente. Mi interés al hacer esto es profundizar un poco más en lo que pueden ser prácticas arquitectónicas desde mundos rurales, desde perspectivas de ecología política feminista y desde el deseo de poesía. Son puntos de vista en los que me he situado, motor de los trabajos de prueba y error a continuación expuestos. Y son puntos de vista periféricos, en los bordes de la disciplina arquitectónica (principalmente los dos primeros).

Si este documento tuviera que formularse en clave de pregunta sería:

¿Cuales son los procesos y resultados de proyectar arquitectura desde aquí? Trataré de responder definiendo estos bordes.

\section{Imagen 1}

Diagrama de experiencias personales en torno a los oasis desde 2004 a 2011. Primer documento explicativo del PFC titulado "Cuatro maneras de caminar por un oasis".

\section{Imagen 2}

Diagrama de experiencias personales en torno a la comarca de La Serena desde verano del 2015. Compartido en el blog personal "Des(de los) bordes".

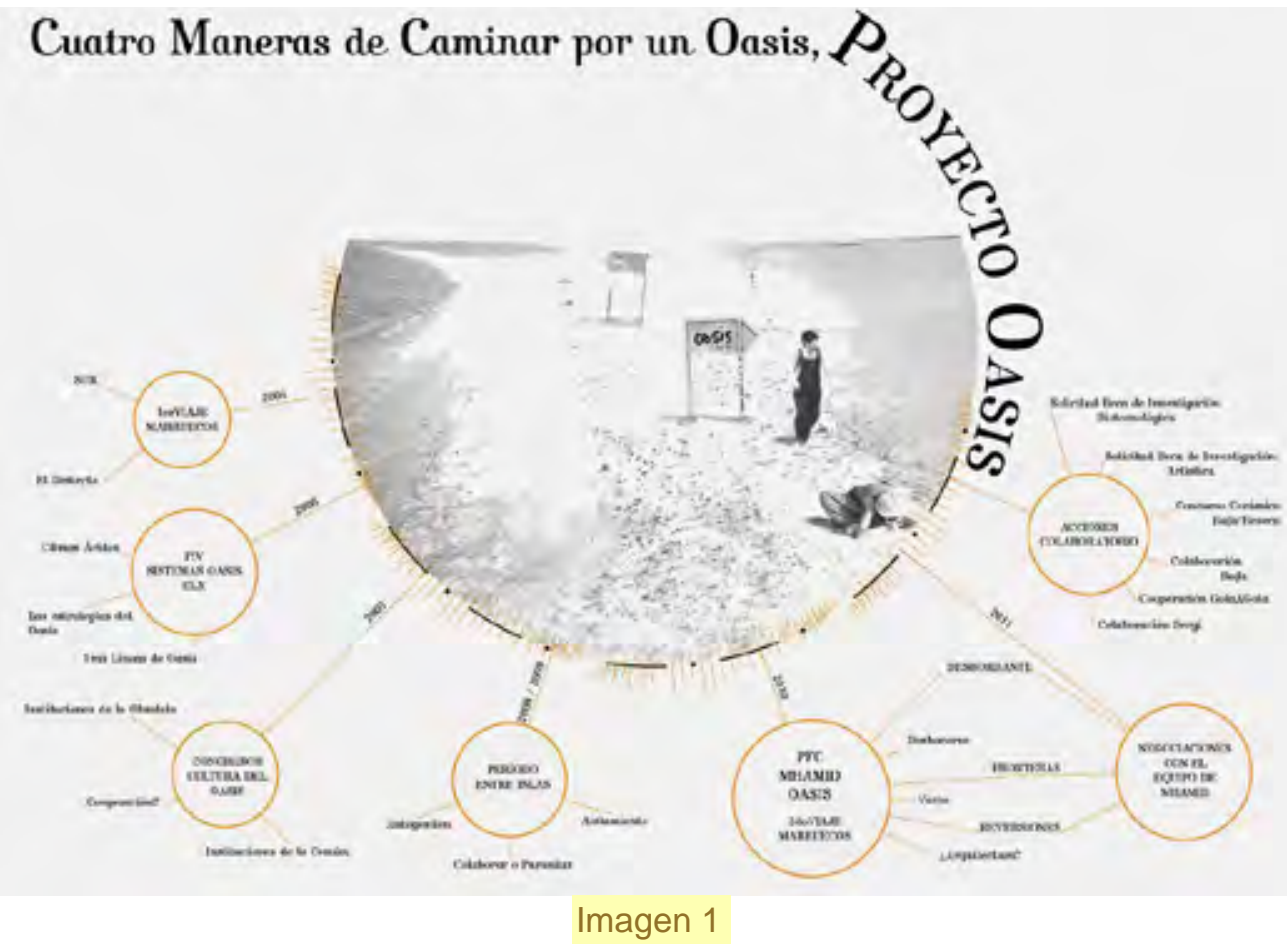

Imagen 1

Imagen 2

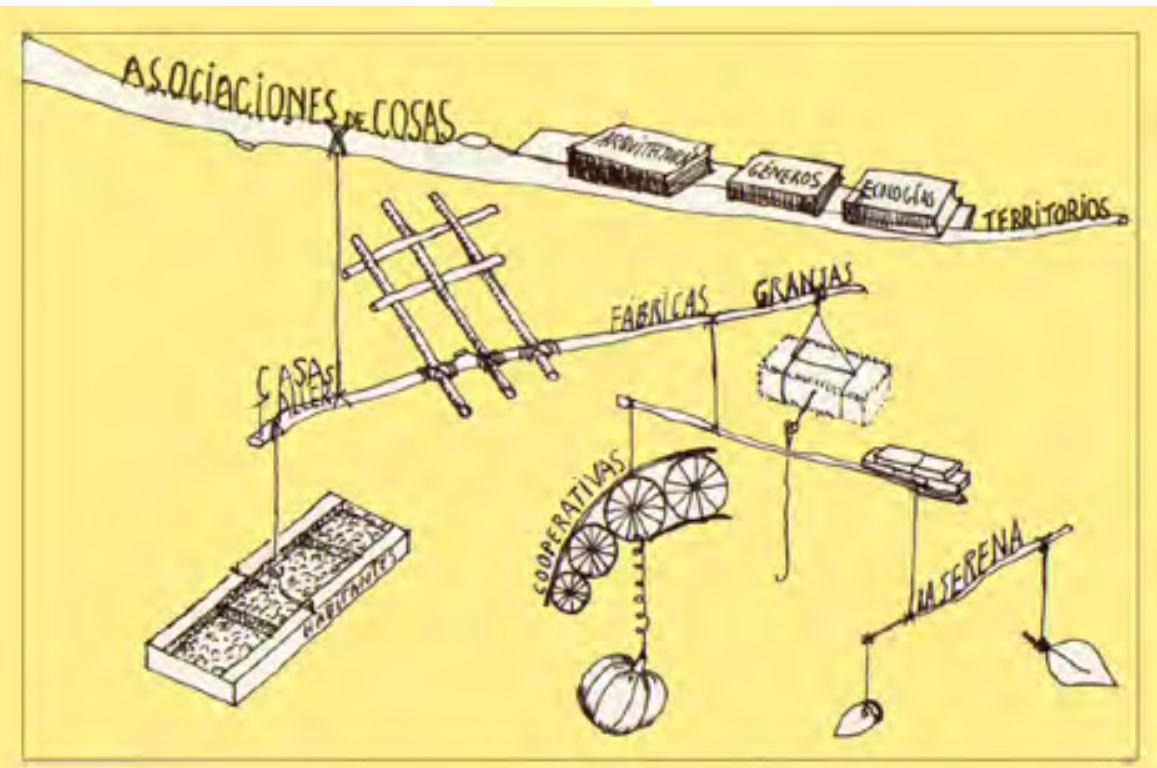

\section{$E$}




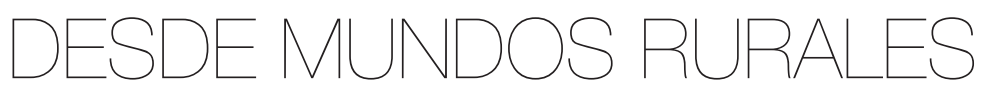

Rural es un término complicado, usado demasiado cómodamente como todo aquello opuesto a lo urbano o a la ciudad. Para muchas personas esta dicotomía ya no tiene sentido, porque sabemos que los límites son difusos y que han desbordado a las definiciones oficiales. Muchos autores consideran que se puede llevar una vida urbana viviendo en medios rurales y viceversa, y que esto es lo emergente y lo deseable. Si la vida urbana se caracteriza para autores como Manuel Delgado, François Ascher y tantos otros, por la movilidad, la cantidad y la diversidad de relaciones sociales diarias, las tecnologías de la comunicación y del transporte de cosas han permitido formar comunidades translocales desarrolladas tanto en entornos físicos como virtuales. Una de sus formas más deseables sería aquella que Fatima Mernisse llamaba las "sociedades cosmocívicas". Cuando alguien forma parte de estas comunidades, de manera intensa y dedicada, podemos decir que dicha persona desarrolla su identidad relacional, aquella en que las personas no pueden entenderse a sí mismas sin sus vínculos con la comunidad, (una identidad considerada propia de las sociedades premodernas), en coexistencia con su identidad individualizada, (propia de las sociedades modernas).

Pero volvamos a esas definiciones oficiales, menos dadas a la ambigüedad. Según éstas, por ejemplo, el $90 \%$ del territorio español es "medio rural" y uno de los parámetros que lo caracterizan es la baja densidad de humanos: se vive en un mundo rural cuando la densidad de población (humana) es inferior a 100-150 hab/km2. Suele suceder que a menor densidad de humanos, mayor densidad de flora, fauna, rocas, y otras cosas en general consideradas dentro de la categoría "naturales" y por tanto la intensidad de la interacción con ellas puede ser también mayor. Todas estas interacciones están marcadas por tecnopolíticas que definen las formas de relación en un entorno rural. Tecnopolíticas para la clasificación y gestión de los espacios de producción agropecuaria, los espacios protegidos, los espacios urbanizados...

Me interesan estas formas de coexistencia, entre identidades relacionales e identidades individualizadas, dentro de comunidades de cosas en el medio rural donde los elementos interactuan a través de tecnopolícas. Y me interesan sobretodo aquellas que tratan de desarrollar formas colaborativas de habitar, frente a las formas de dominación. Estas formas de coexistencia son en realidad singularidades rurales.
Un poblado 0ASIS en la $3 \mathrm{ra}$ REVOLICTÓN TRRANA MODERnoNA

Imagen 3

Esquema comparativo de los paradigmas que definen la ciudad y sociedad mercado (premoderna) frente a la ciudad y sociedad hipertexto (postmoderna o hipermoderna). Extraido del libro "Los nuevos principios de urbanismo" de Ascher.

Documento del PFC usado para entender la mezcla y transformación de paradigmas que se dan en algunas sociedades por las que no pasó la era industrial y a las que si les ha llegado la era digital, como en el caso del oasis objeto del PFC.

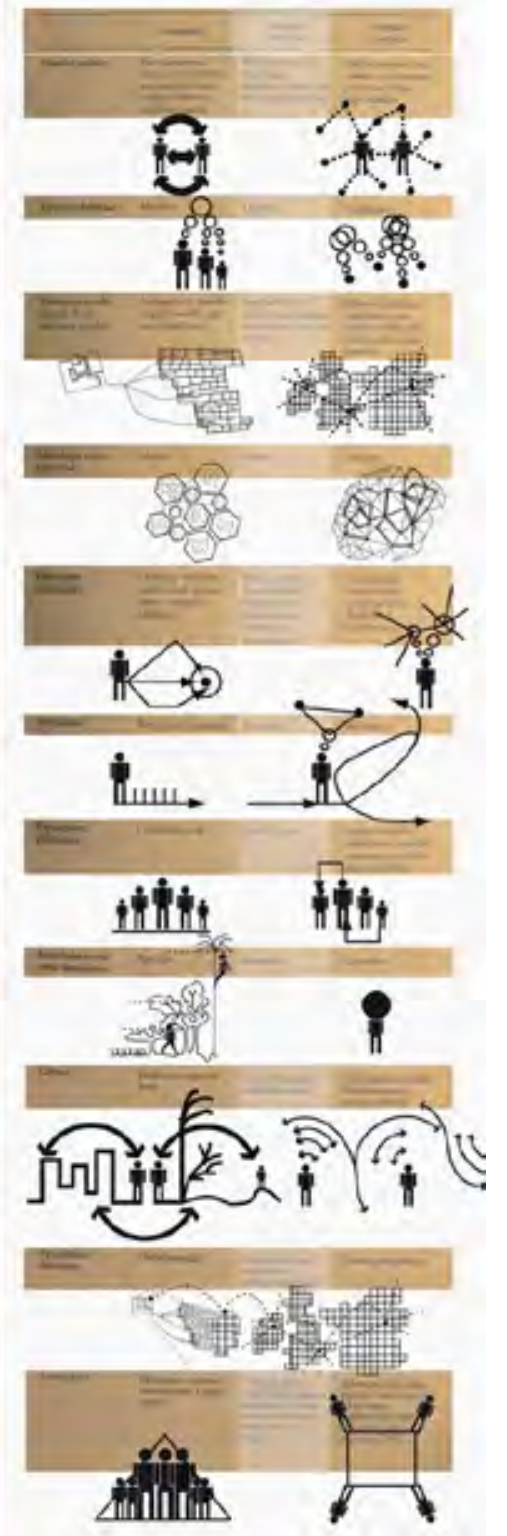




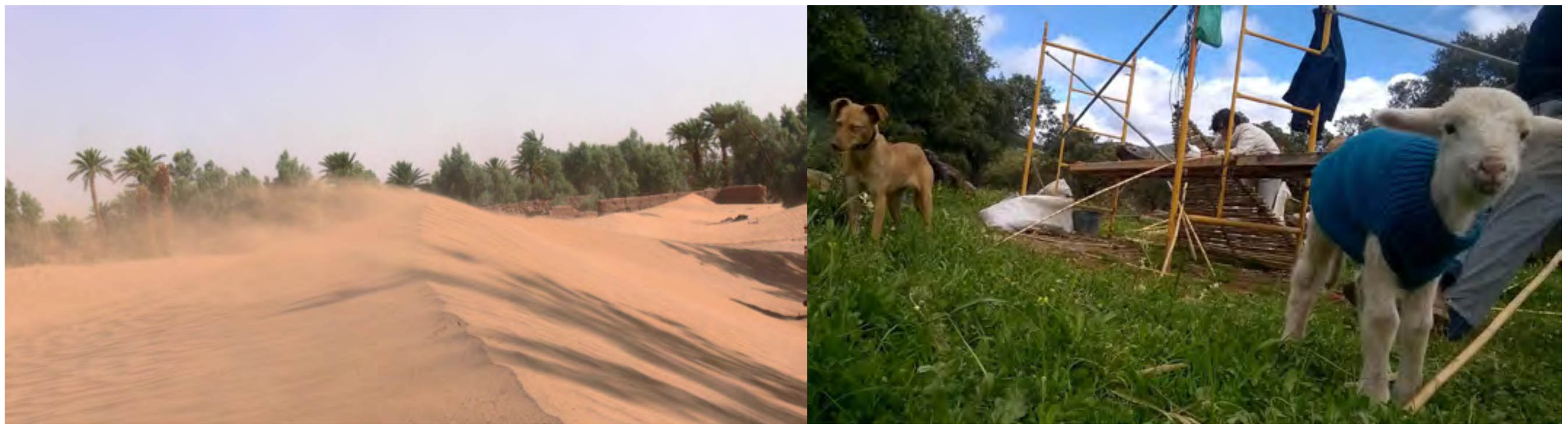

Imagen 4

Tormenta de arena en los bordes del último oasis del Valle del Draá, al sureste de Marruecos, decreciendo por el avance del desierto. Objeto del PFC, habitado po población rural, árabe, musulmada y bereber en la frontera sin resolver con Argelia. Imagen 5

Algunas de las acciones-interacciones entre diferentes elementos del oasis, humanos y no humanos, propuestas para construir un futuro diferente a la desaparición.

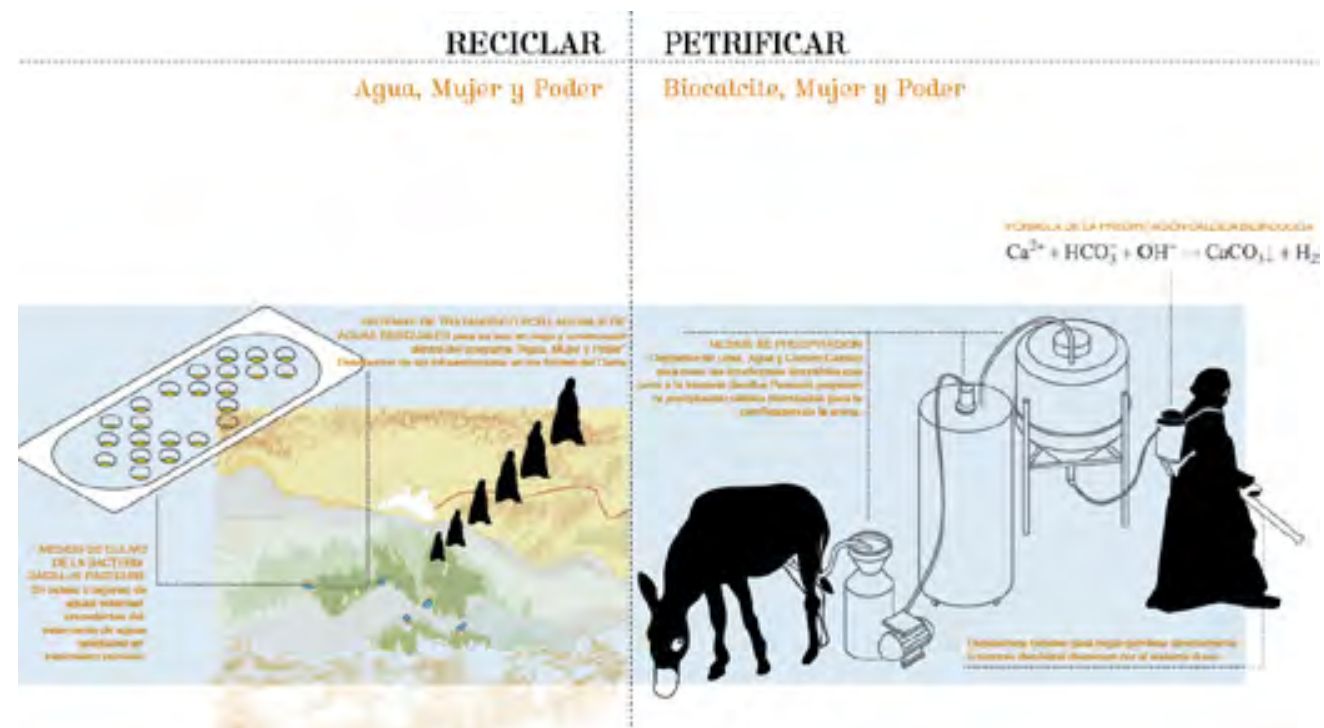

Imagen 6 está experimentando y proponiendo otras formas de habitar y gestionar estos sistemas, actualmente sobreexplotados o abandanados.

Imagen 7

Propuesta de refugios para las dehesas extremeñas. Un dispositivo para activar la conversación sobre estos entornos y la investigación en tecnologías de Bioconstrucción Prefabricada con materiales situados.
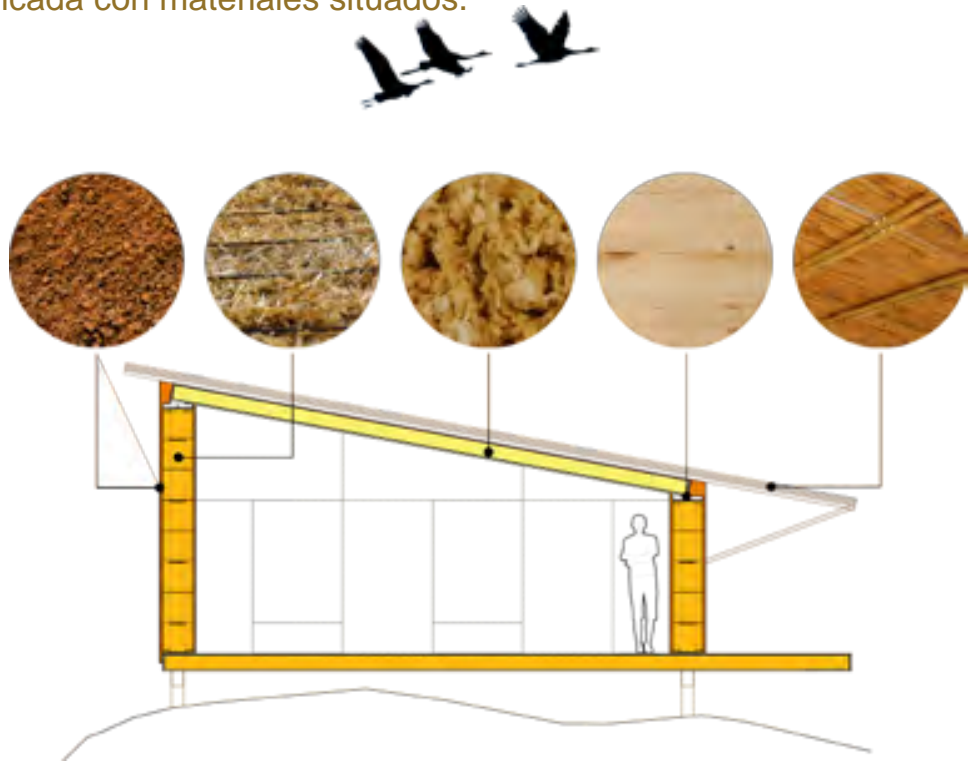

Jornada de trabajo colectivo en una dehesa en Salvaleón, extremadura, donde se 

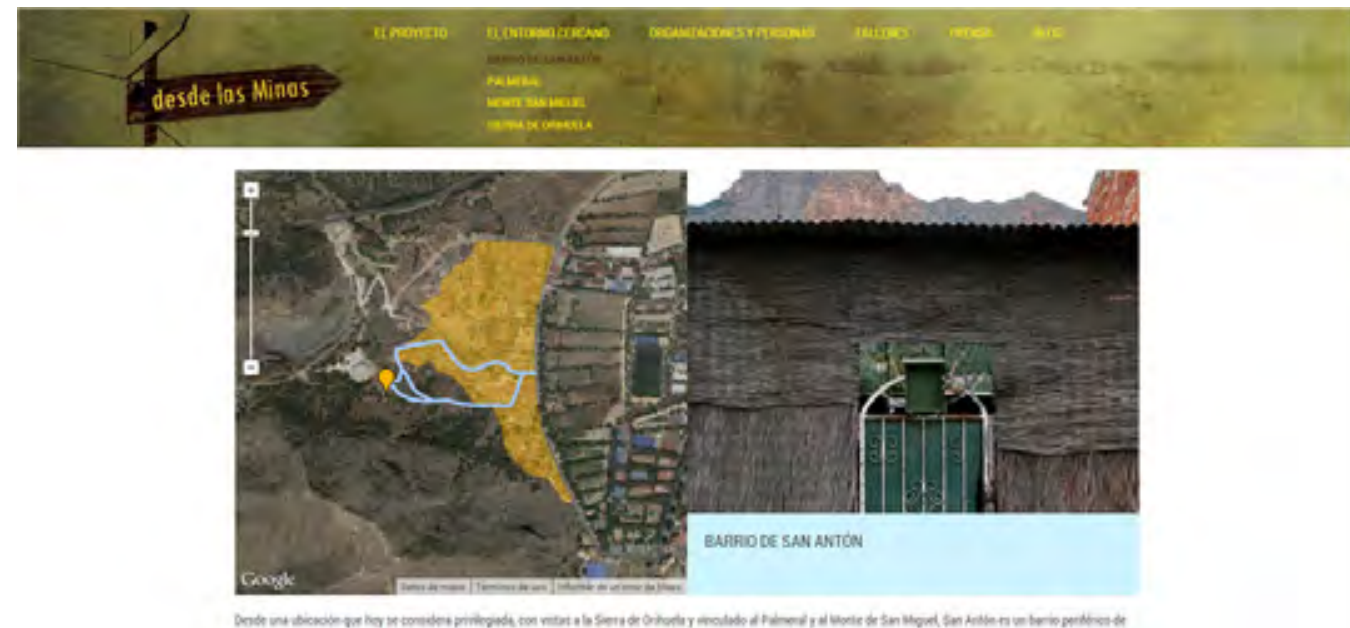

Imagen 8

Plataforma online con el pasado, presente, y posibles futuros de Las Minas de San Antón relacionadas con su entorno, en Orihuela, Alicante. Una de las herramientas desarrolladas para el proyecto de revitalización de las minas. Un proyecto de MULTIHABITAR

Imagen 9

Diagrama de relaciones de las ruinas (el Horno de Aludeles y la casa de los mineros) con su entorno para un proceso de revitalización colectivo.

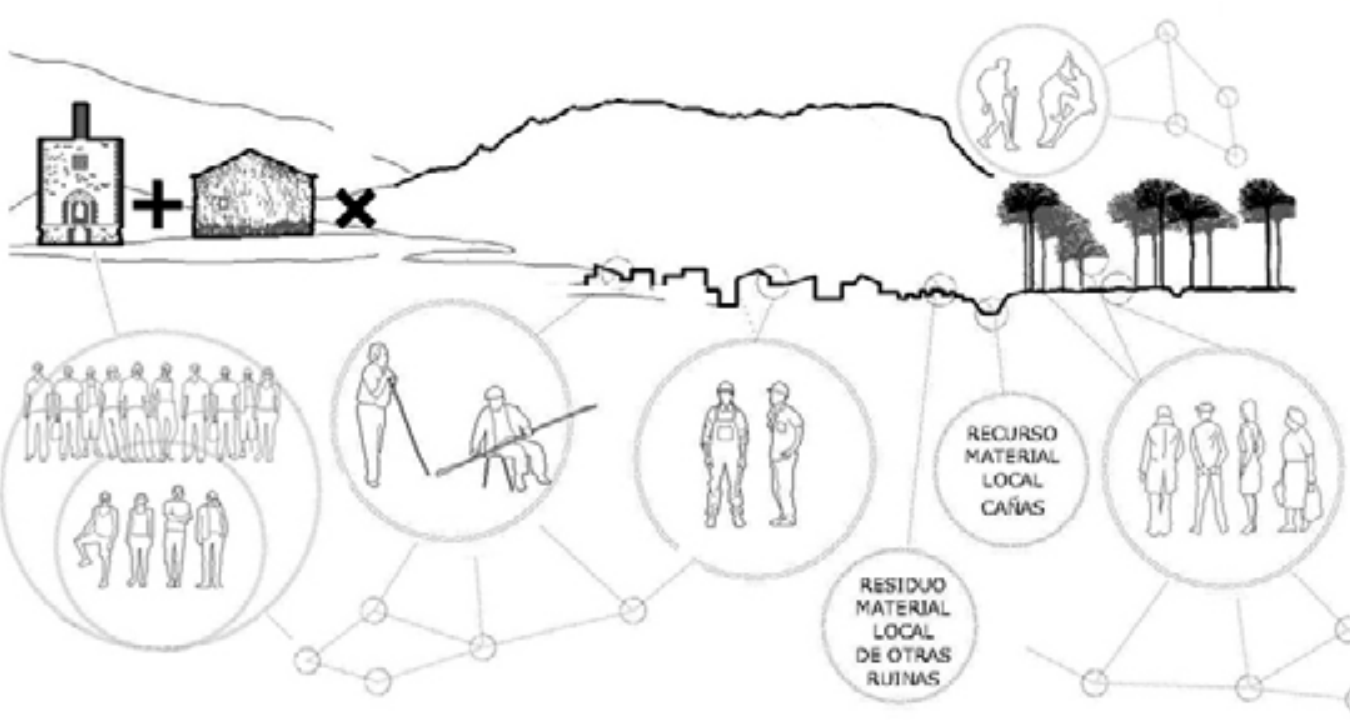

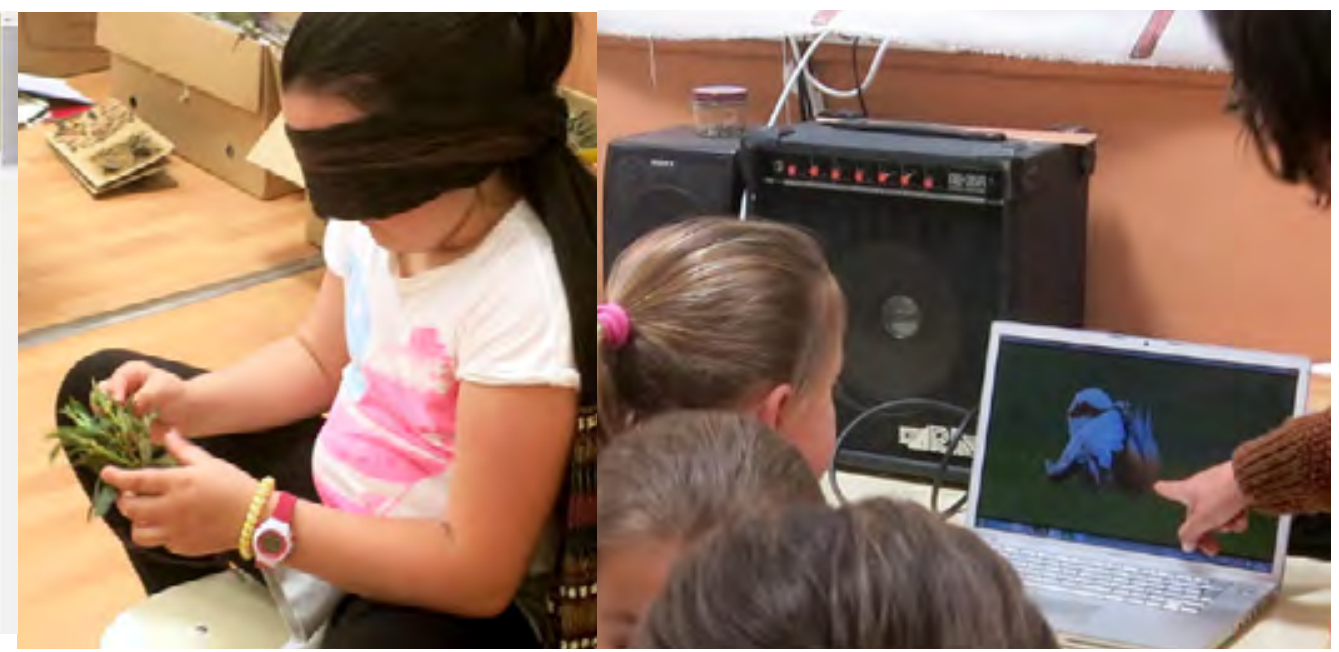

Imagen 10

Talleres para descubrir desde los sentidos y la fantasía, la comarca de La Serena sin salir de un aula. Un proyecto de MULTIHABITAR

Imagen 11

Una casa de piedras y lana de oveja. Trabajo realizado por uno de los niños participantes al taller dentro de la dinámica: "Cuaderno de un viaje imaginado".

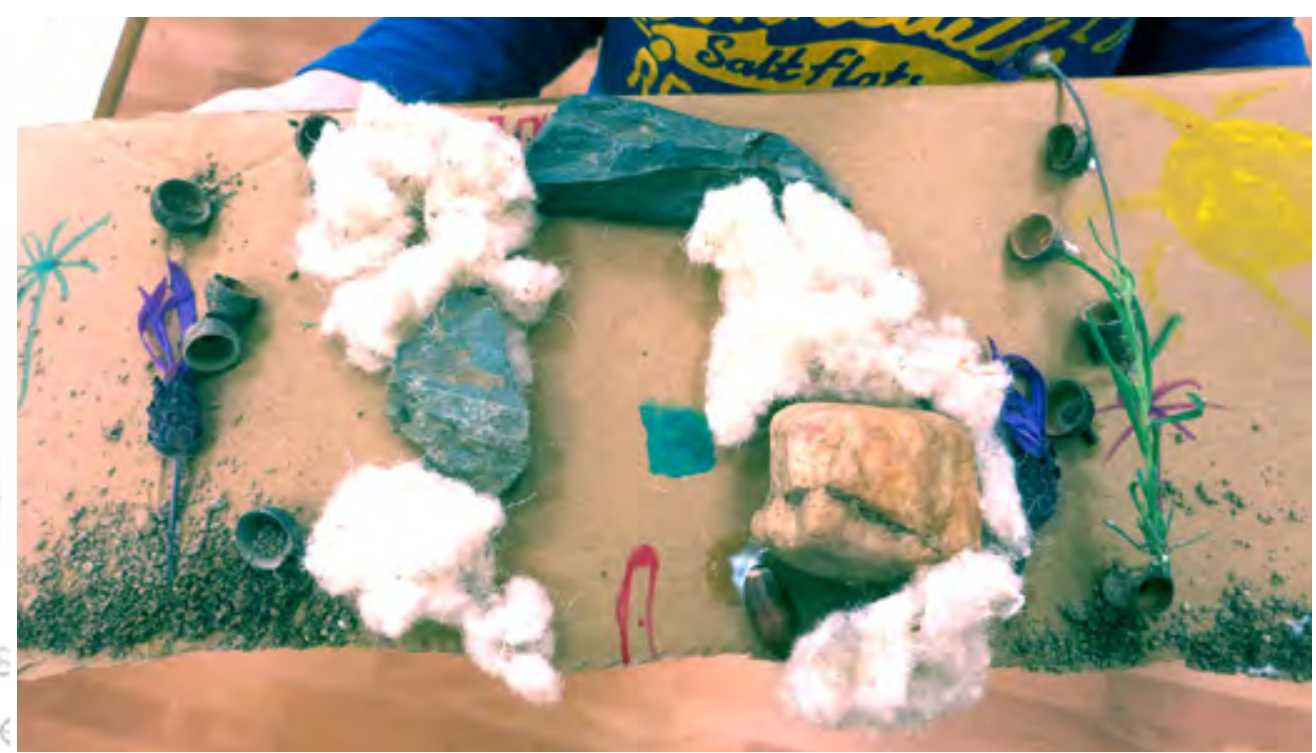




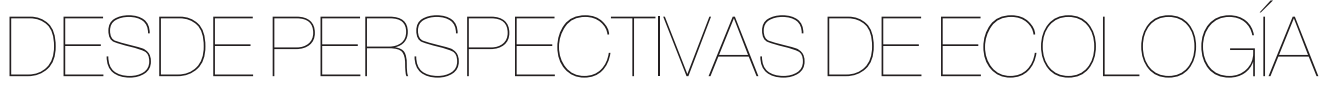

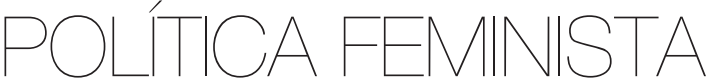

Si el término "rural" es incómodo, los términos "ecología política feminista" lo son aún más. Llegué a ellos releyendo durante el PFC un libro titulado "El ecologismo de los pobres", de Joan Martínez Alier, y descubriendo la novela "Sueños en el Umbral" de la escritora, socióloga, experta en El Coran y feminista, Fatema Mernissi. Ambas lecturas tratan cuestiones controvertidas: que el ecologismo puede ser cosa de pobres y que una marroquí que no reniega de su creencia religiosa puede ser feminista. Pero, para ser exactas, al feminismos no llegué hasta que no estuve en el oasis.

La ecología política trata los conflictos ecológicos distributivos. Trata de responder, a nivel local, regional y global, a preguntas como: ¿Quién tiene el poder de gestión de los recursos ambientales? ¿Cuál es la interrelación entre valores no materiales como lo sagrado y el interés material de asegurarse el sustento? ¿Quién tiene el poder de imponer lenguajes específicos de valoración? ¿Quién tiene la capacidad y el poder de simplificar la complejidad desconsiderando la validez de otros puntos de vista? Propone democracias participativas y está influenciado por movimientos feministas, libertarios...dando soporte a las principales corrientes ecológicas: el "culto a lo silvestre", el "evangelio de la ecoeficiencia" y el "ecologismo de los pobres", aunque su campo de trabajo principal esté en éste último. Las diferencias entre estos movimientos están precisamente en las formas de relacionarse con otras ciencias, con el feminismo, el poder del estado o la religión, los intereses empresariales, las cosas no humanas... La primera, el "culto a lo silvestre", es una sacralización de la naturaleza que lleva como línea de acción su conservación mediante la protección, manteniendola fuera del mercado. Es un actitud biocéntrica. Por el contrario el "evangelio de la ecoeficiencia" cree en el desarrollo sostenible al que se llega por eficencia técnica. Lo sagrado, lo subjetivo, para este credo no existe. Es una actitud logocéntrica y tecnócrata que lleva al conflicto porque lo sagrado realmente existe en muchos contextos y su valor económico es incommensurable. El ecologismo de los pobres y las minorías nace de dichos conflictos ambientales a nivel local, regional, global, causados por un crecimiento económico basado en la desigualdal social y la dominación. Los actores principales de estos conflictos muchas veces no se consideran a sí mismos ecologistas, ni usan un lenguaje ecologista. Pero sus luchas son luchas por la justicia ambiental.
Aún no estando personalmente posicionada en ninguna de estas corrientes, la realidad es que he vivido y trabajado en lugares rurales, geográfica y políticamente periféricos, empobrecidos y con conflictos ambientales que comprometen el futuro del entorno: desde la desaparación de los oasis a la desaparición de las dehesas...por lo que algunas de las prácticas arquitectónicas planteadas para estos lugares siguen estrategias del ecologismo de los pobres, hacia formas de hacer arquitectura, ciudad y territorio donde la sostenibilidad es una cuestión participada, como herramienta de cohesión y emancipación de las comunidades. El feminismo, como teoría y activismo que ha trabajado por la deconstrucción del logocentrismo, así como por la construcción de subjetividades emancipadas, diversas, individuales y comunitarias, es fuente de modos de hacer fundamental para el proceder de la ecología política.

Una cuarta corriente, alternativa a estas tres, y que podría superponerse a elas, sería la que propone Jane Bennet en "Vibrant Matter. Una ecología política de las cosas", donde la materia, humana y no humana, es considerada con agencia propia. Este cambio de paradigma, de forma de percibir lo que nos rodea, incluyendonos a nosotros, ya no considerando que hay cosas inertes, no vivas, sino que todo esta vivo, interactuando y afectandose, podría hacernos entender mejor el funcionamiento de la materia y por tanto desarrollar de forma más natural modos de producción y gestión más ecológicas y sustentables. La teoría de los afectos, desarrollada por diferentes corrientes feministas, juega un papel fundamental en este cambio de paradigma:

"I continue to think of affect as central to politics and ethics...I now emphatize even more how the figure of enchantment point in two directions, the first toward the human who feel encanched and whose agentic capacities may be thereby strengthened, and the second toward the agency of the things that produce (helpful, harmful) effects in human and other bodies" (Vibrant Matter, a political ecology of things. Jane Bennet, 2010) 


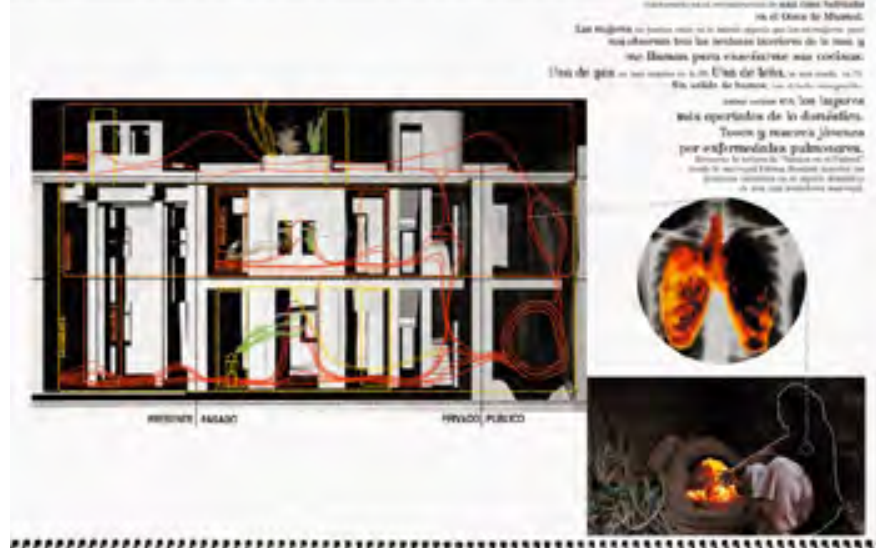

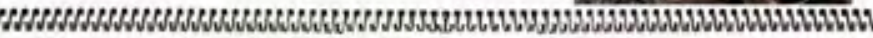

\section{COCINAR.}

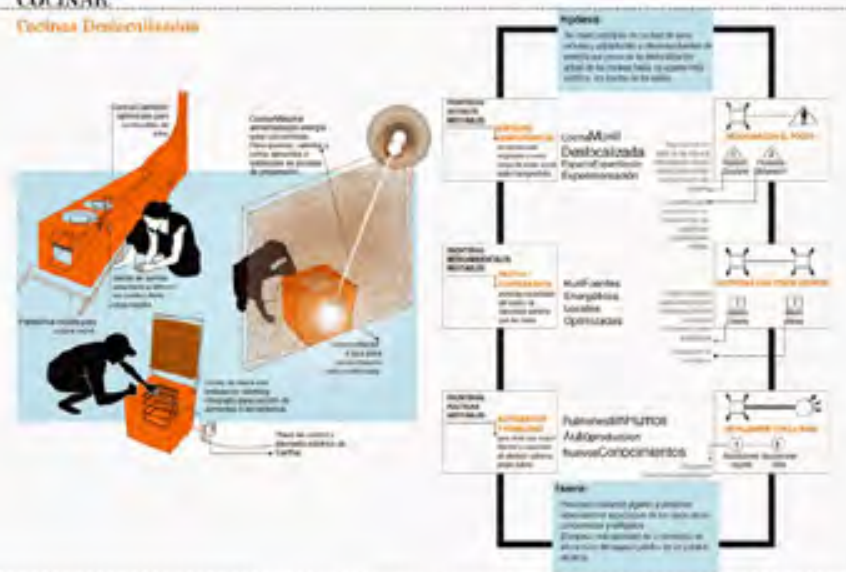

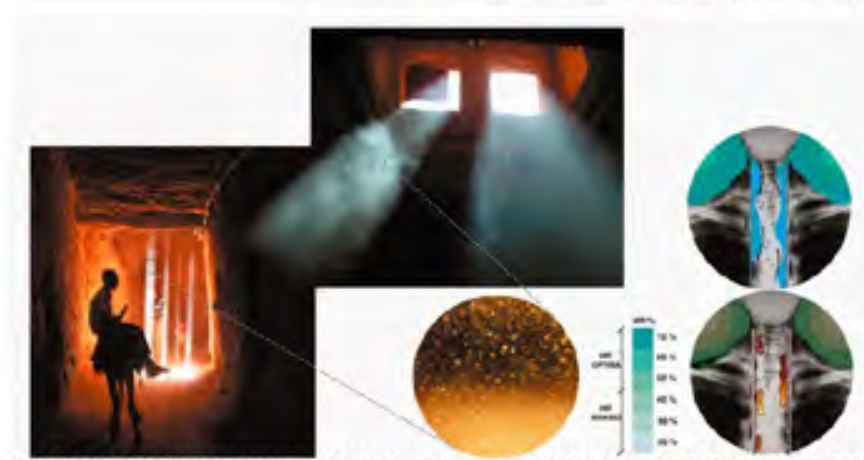

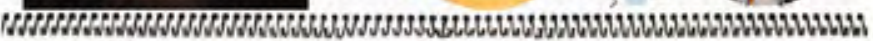

POROSTAR

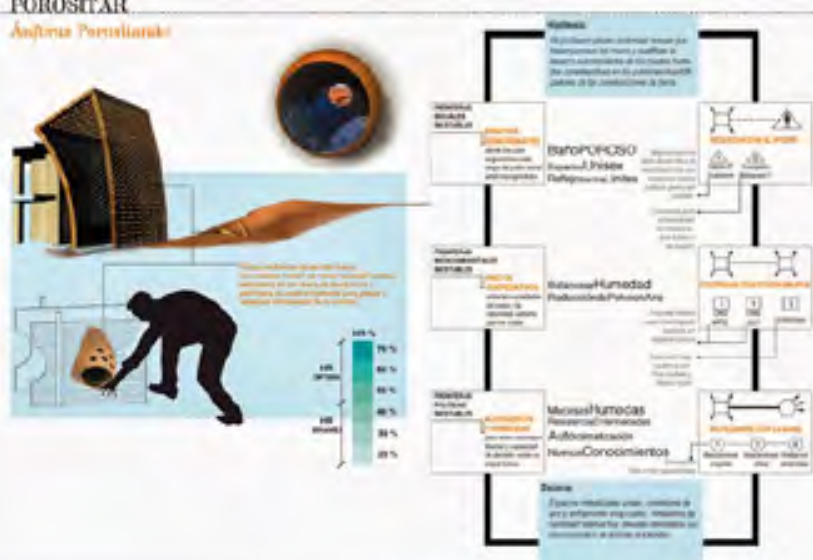

Imagen 12

Cuaderno de viaje. Uno de los documentos fundamentales dentro del PFC. La pregunta motor en esta parte del proyecto fue: ¿Cómo colaborar con un oasis desde los afectos cotidianos? En la parte superior registré algunas de esas experiencias cotidianas vividas. En su mayoría se trataba de las tareas domésticas, realizadas por las mujeres, para mantener vivo el oasis. En la parte intermedia del documento, lanzaba propuestas para la acción directa sobre dichas tareas a través de la construcción colectiva de nuevos dispositivos domésticos que afectan de manera directa en la gestión de elementos tan importantes como el agua, el viento, la arena, los alimentos... La realización de estas acciones, y la puesta en práctica de estos dispositivos, construiría por sí mismo los escenarios de transformación en la relación con los elementos, el espacio físico y político del oasis.

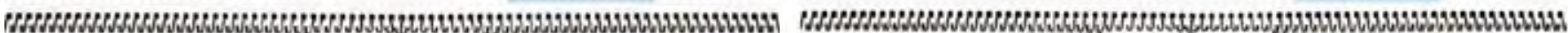
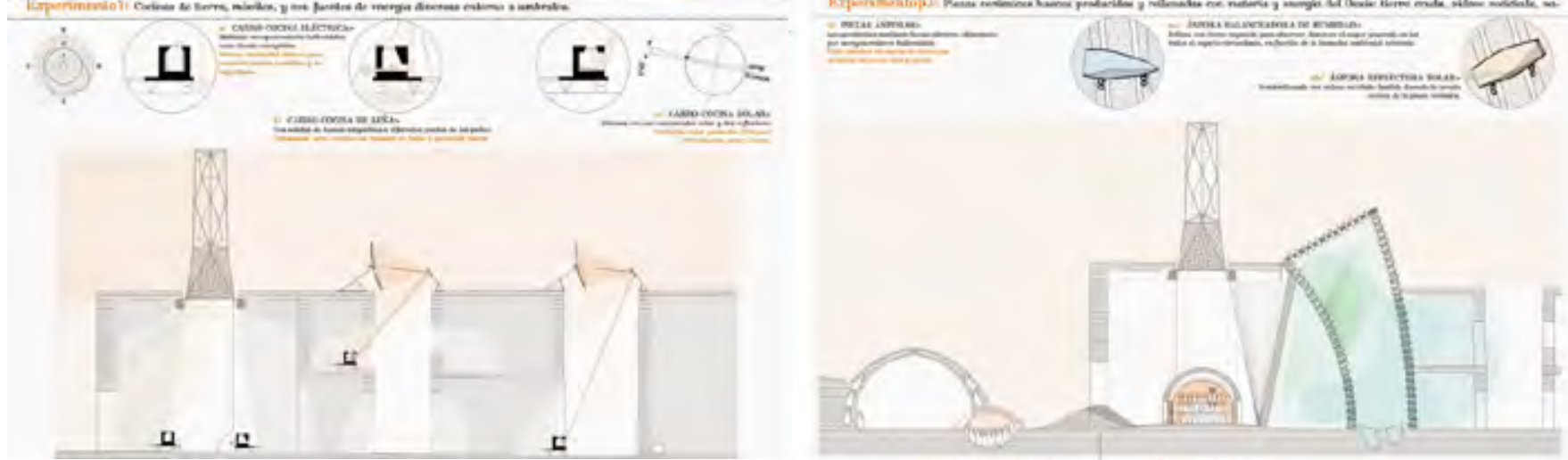
Imagen 13

Fotos del proceso de construcción colectiva, y de los parlización impartido por MULTIHABITAR en la finca La Jara, Jerez de la Frontera, para la formación de miembros de la cooperativa La Yerbabuena. Esta cooperativa está conformada por personas seleccionadas por estar en riesgo de exclusión social, para ser formados en técnicas de producción agroecológicas. Pero el proyecto inicial quiso crecer, hacia una mayor resiliencia de los participantes, aprendiendo más oficios desde una perspectiva ecológica. Servicios que podrían ofrecerse desde la cooperativa.

Los talleres debían servir también para la construcción de tres espacios acondicionados necesarios para la finca: un espacio de bienvenida, un espacio de venta de productos, y un espacio para su consumo. El objetivo es IIy llevando visitas escolares, convirtiendo este lugar durante mucho tiempo abandonado, en un espacio público rural reconstruido colectivamente, donde aprender otras formas de habitar. ticipantes, al taller de técnicas de bioconstrucción y reutievar actividad a la finca, realizando un mercado mensual
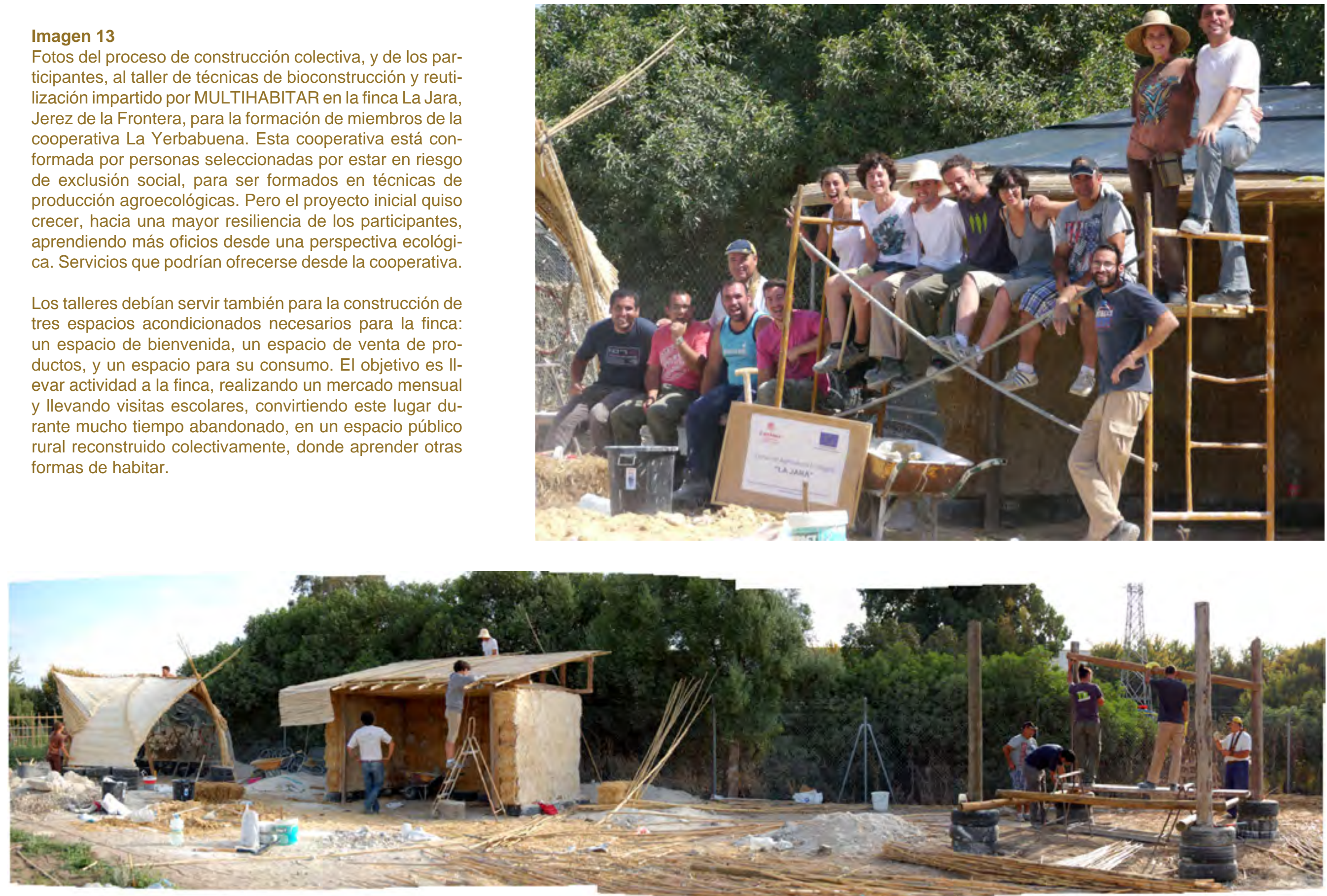


\section{CUESTIONES TÉCNICAS SOBRE LAS LOSAS ALVEOLARES DE MADERA CON AISLAMIENTO DE LANA DE OVEJA}

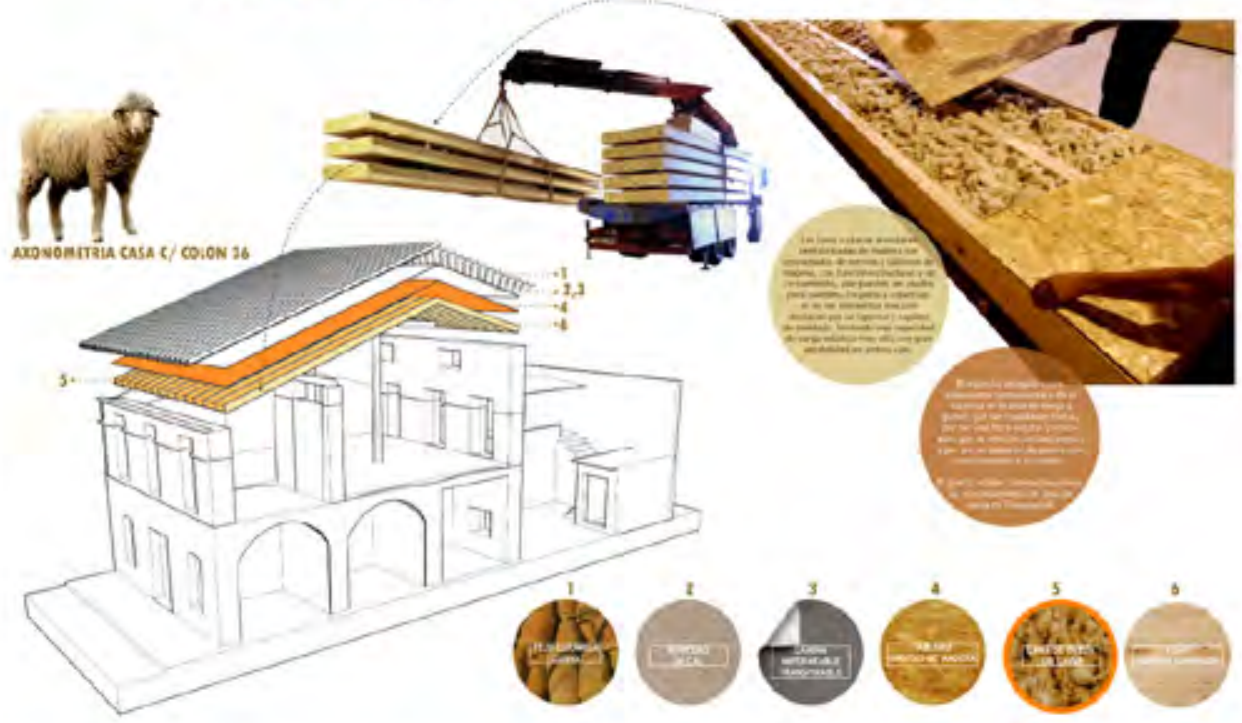

CUALIDADES TÉCNICAS DE LA LANA DE OVEJA COMO AISLANTE

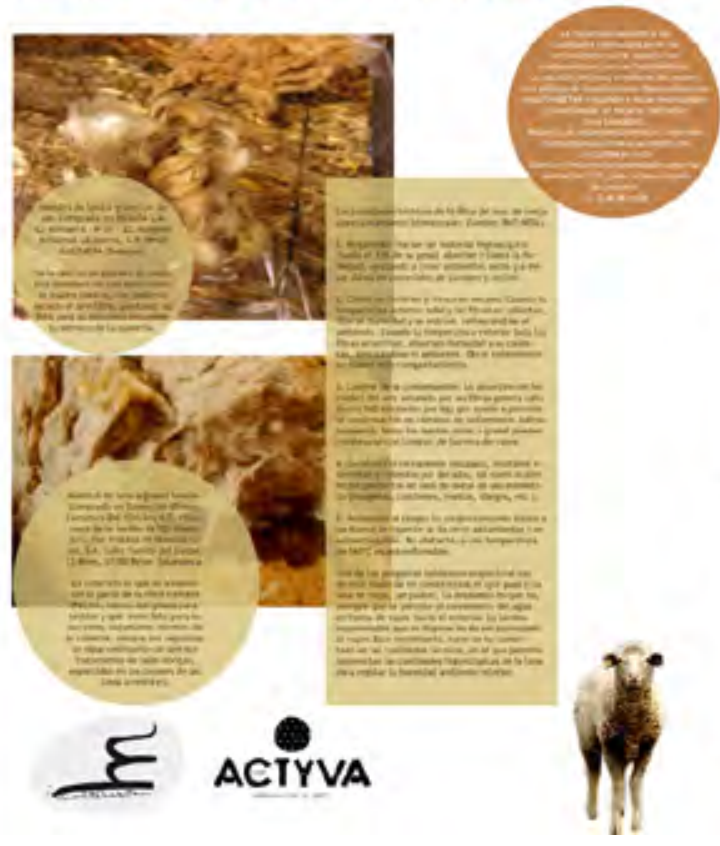

Imagen 14

Paneles y maqueta realizados para la exposición en la feria del ganado ovino, celebrado en Castuera, Badajoz, del sistema de construcción desarrollado por MULTIHABITAR empleando lana de oveja como material de aislamiento. La oveja merina es característica en toda extremadura, siendo su lana un producto local abundante y de gran calidad. Desde MULTIHABITAR investigamos formas para su aplicación también en construcción, como una manera de contribuir al desarrollo de la economía local ampliando mercado y cerrando ciclos de producción, pues la parte del bellón empleado es la llamada "puncha", que al ser de fibras cortas se deshecha para la hilatura. Es además una contribución a la construcción de hábitats más saludables, y es que las propiedades de la lana la convierten en un material muy deseable.

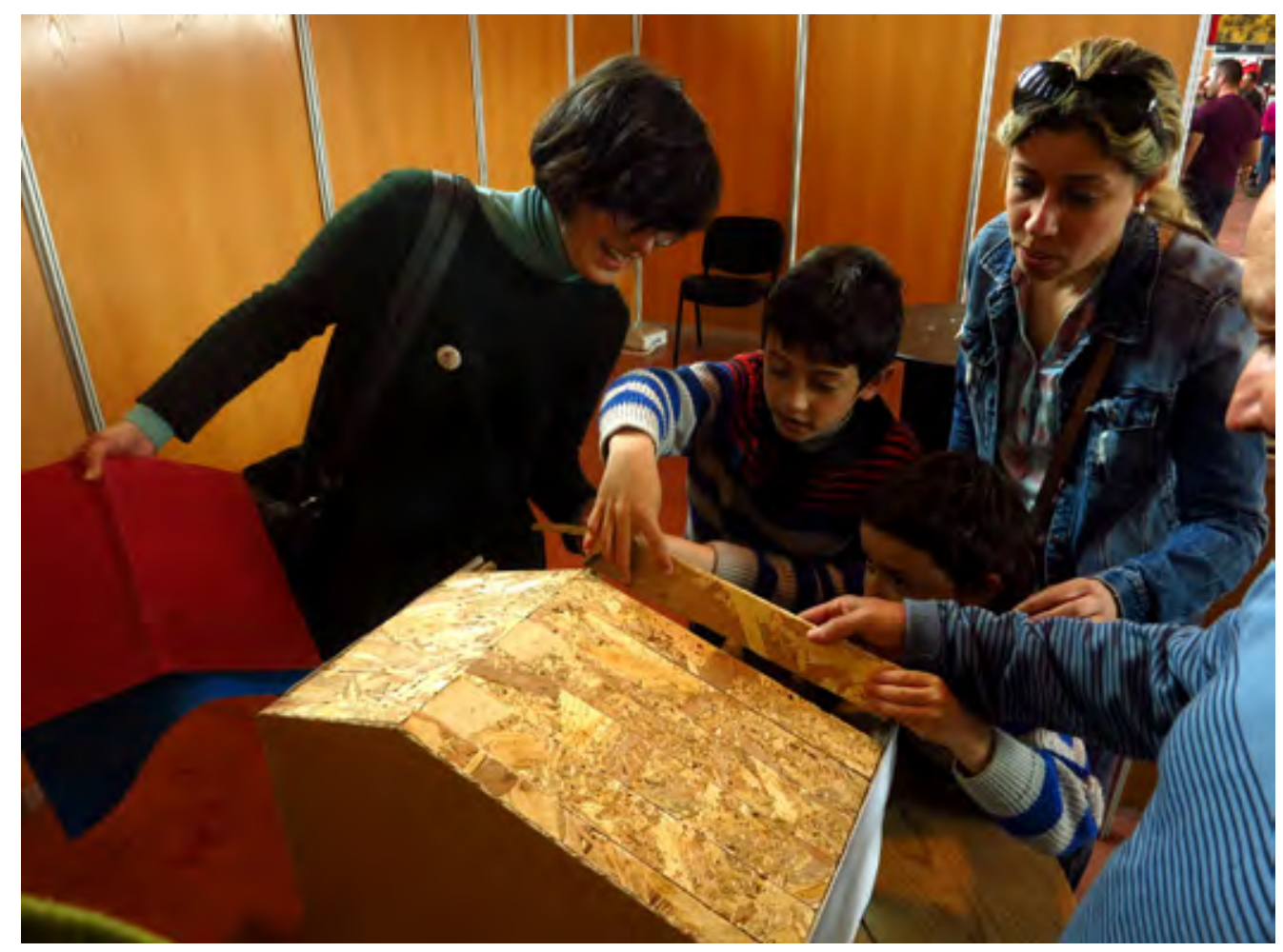




\section{DESDE EL DESEODE POESÍA}

Poesía, si, por su capacidad para afectar. El término procede del griego moínбıৎ "creación", mediante el latín poesis, que quiere decir "hacer", y se refiere a convertir pensamientos a materia. Convertir pensamientos a materia pero con poesía, diría yo. Así que para salir de este bucle me hago eco de las siguientes reflexiones, escritas por Manuel Delgado ,en su blog, sobre la teoría general de las prácticas y las formas artísticas de Levi Straus:

"Diríamos más bien que Lévi-Strauss se conforma, a la hora de proponer una teoría general de las prácticas y las formas artísticas, con los esbozos trazados en el primer capítulo de El pensamiento salvaje (FCE, México DF, 2006 [1963]) ... En ellos se establece que el arte se colocaría a medio camino entre el conocimiento científico y el con ocimiento que podríamos llamar mítico o mágico, siendo el papel del artista algo instalable entre el del sabio y el del narrador de mitos o el hechicero de otras sociedades."

Mitos y cuentos en una comunidad constituyen lo poético común, aquello que tiene la capacidad de crear vínculos afectivos y de identidad, reapropiables, reinterpretables. Así pues, buscamos prácticas arquitectónicas con capacidad para crear o contribuir en la construcción de mitos, cuentos, de lo poético común.

¿Y la materia donde queda? En las prácticas que aquí expongo, tanta más poesía cuanta más capacidad tiene el proceso-proyecto desarrollado para actuar en el ciclo de vida de la materia, reubicando material sobrante, en abundancia en el medio y en muchas ocasiones deshechado, sin un lugar en el mundo...

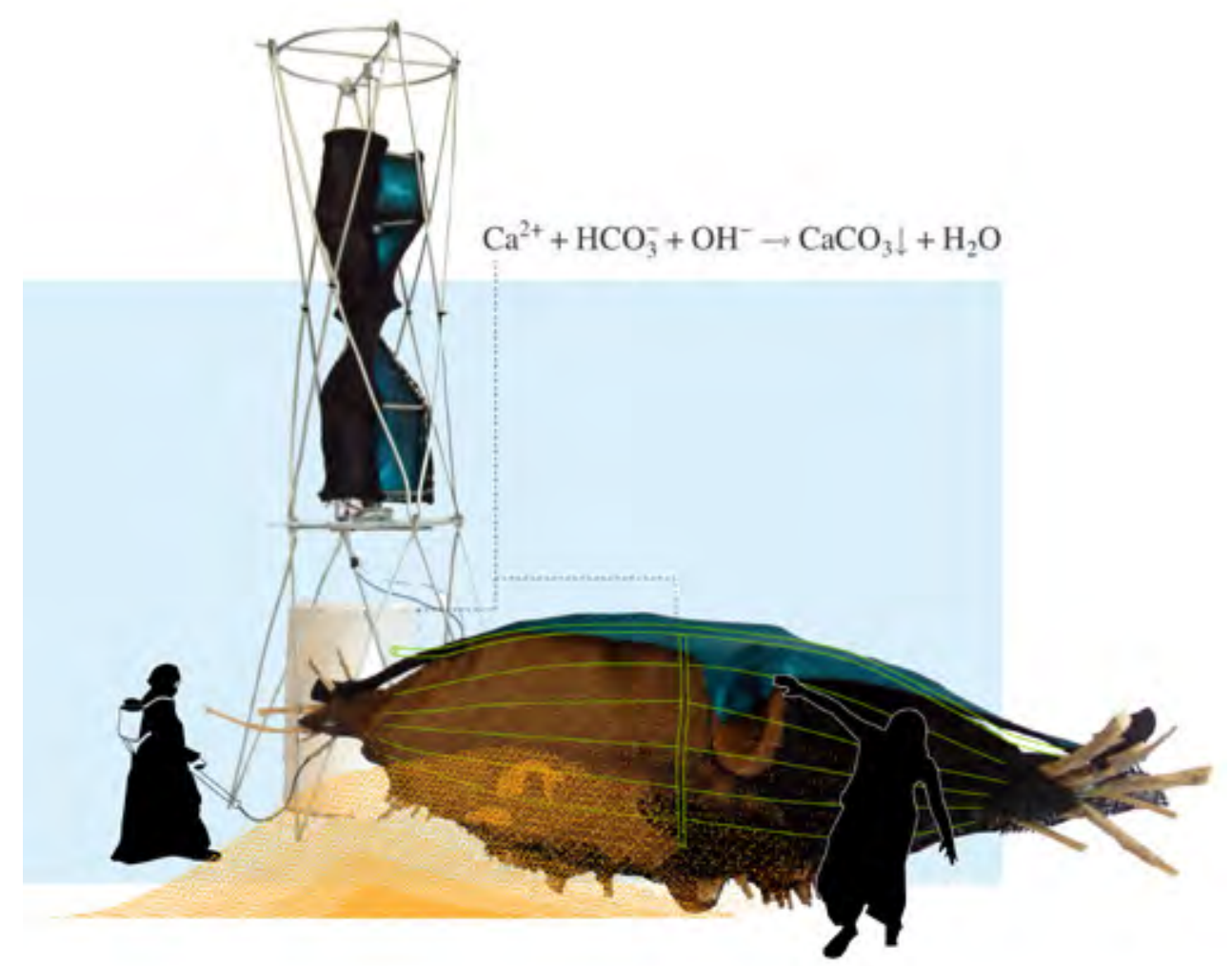




\section{El cuento de los peces del desierto.}

Después de una tormenta de arena, la extranjera anotó en su cuaderno de viaje:

“...un grupo de mujeres llegó al borde entre el oasis y el desierto, a la franja de tierra en peligro de dejar de ser fértil, para tejer hojas de palmera sobre las dunas, como barreras contra la desertificación. Los elementos que mantienen vivo el oasis son las palmeras, los tamarindos y las mujeres. Sin las mujeres el oasis desaparecería en pocos años"

Esta extranjera les propuso experimentar con otros sistemas para evitar el avance del desierto. Propuso tecnologías para reciclar agua y para petrificar arena con biocalcite. Serían necesarios cultivos de la bacteria bacillus, fáciles de obtener en las condiciones climáticas del oasis, depósitos de urea, cloruro cálcico y agua reciclada. Esta es la tecnología que se le ofrecía a las mujeres para su autogestión.

La transferencia de tecnología se realizó a través de talleres de creatividad colectiva, donde las participantes fueron escribiendo las instrucciones para redibujar el borde entre el desierto y el oasis, entre Marruecos y Argelia, entre los espacios públicos y privados...

Los elementos que mantienen vivo el oasis son las palmeras, los tamarindos y las mujeres. Son las mujeres las que cultivan el "vivero de peces del desierto".

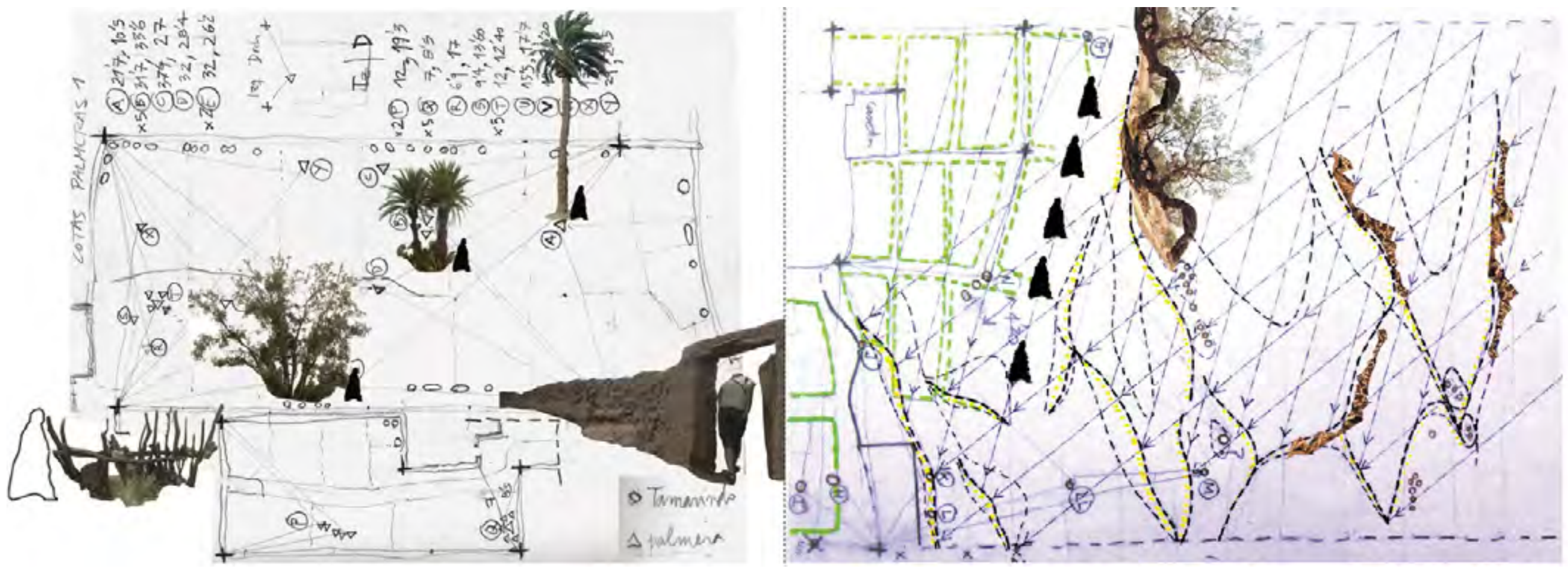




\section{Éstas son las instrucciones acordadas:}

1. Construye sistemas atrapaarena con materiales del oasis.

2. Colócalos en las crestas de las dunas y conéctalos a un sistema de riego con solución de biocalcite.

3. Durante las tormentas de arena, el riego se activará automáticamente mediante turbinas de baja tecnología, construidas también por quienes gestionan el vivero.

4. La arena quedará atrapada en los atrapaarenas, petrificándose en contacto con el biocalcite, y estabilizando el eje central de la duna, que en pocos años dejará de crecer, y por tanto, de avanzar sobre el oasis.

Este "vivero de peces del desierto" no tiene cómo único fin estabilizar la duna. El borde entre el desierto y el oasis se reconfigura con estas tecnologías, creándose un nuevo paisaje, unas nuevas singularidades topográficas, que pueden ser gestionadas como atractor turísti$c o$, ofreciendo al visitante nuevas experiencias en el desierto. Estos peces también están equipados con balizas lumínicas y sonoras, para redibujar, desde sus habitante, la frontera sin resolver entre Marruevo y Argelia.
Instrucciones para Cultibar el Borde entre un Sistema Oasis y un Sistema Dunar
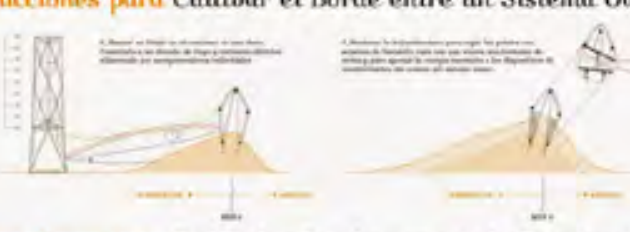

Instruicciones para Redibujar Continuamente la Frontera Virtual entre dos Naciones
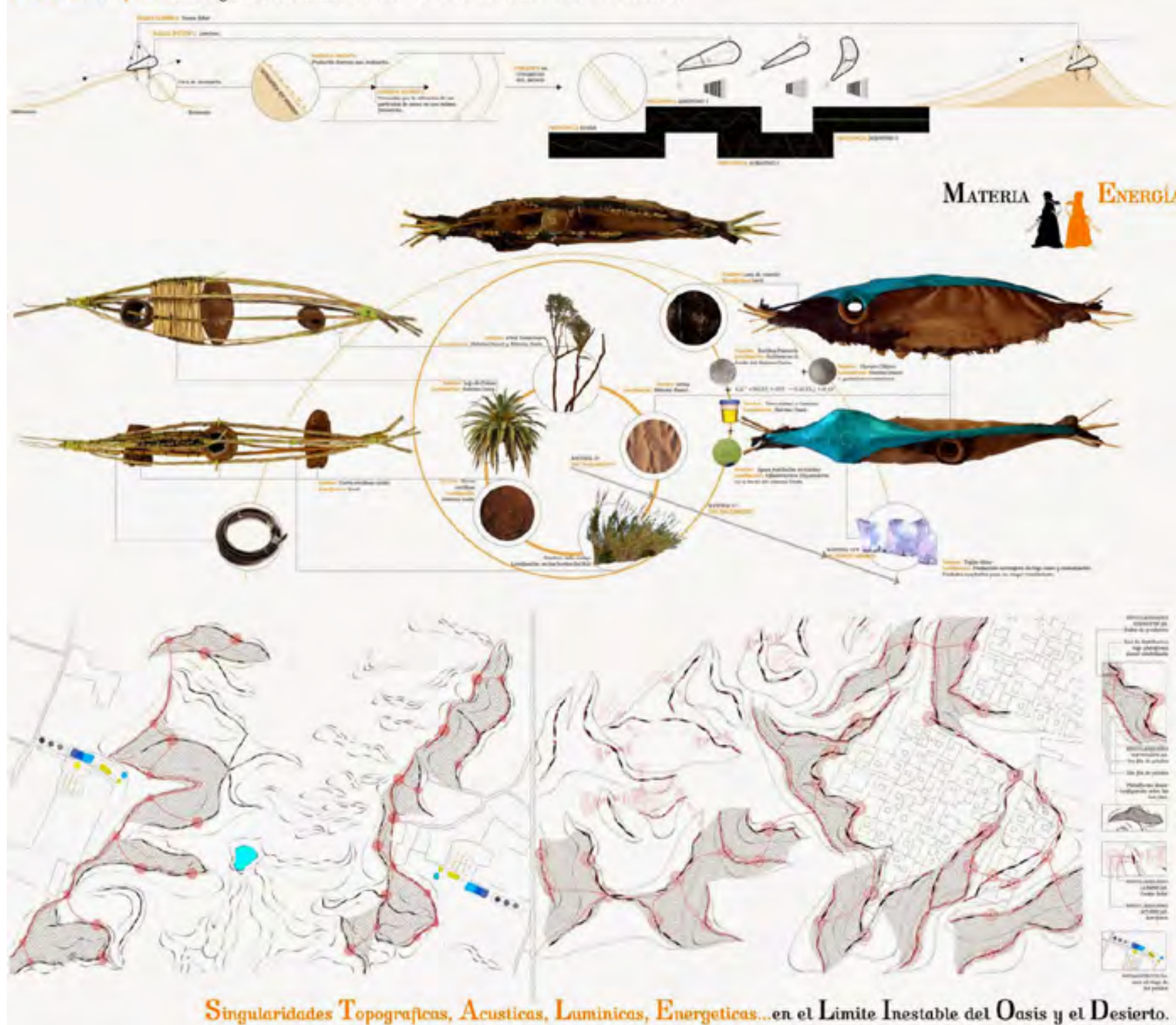
Una cúpula de llantas y otras cosas del montón,

un espacio de bienvenida,

un aula de interpretación,

un secadero de flores,

un espacio de reuniones,

un espacio de celebraciones,

un espacio de sombra,

una construcción icono,

una construcción colectiva,

un espacio de bienvenida.

Un proyecto de MULTIHABITAR

para la Cooperativa La Yerbabuena.

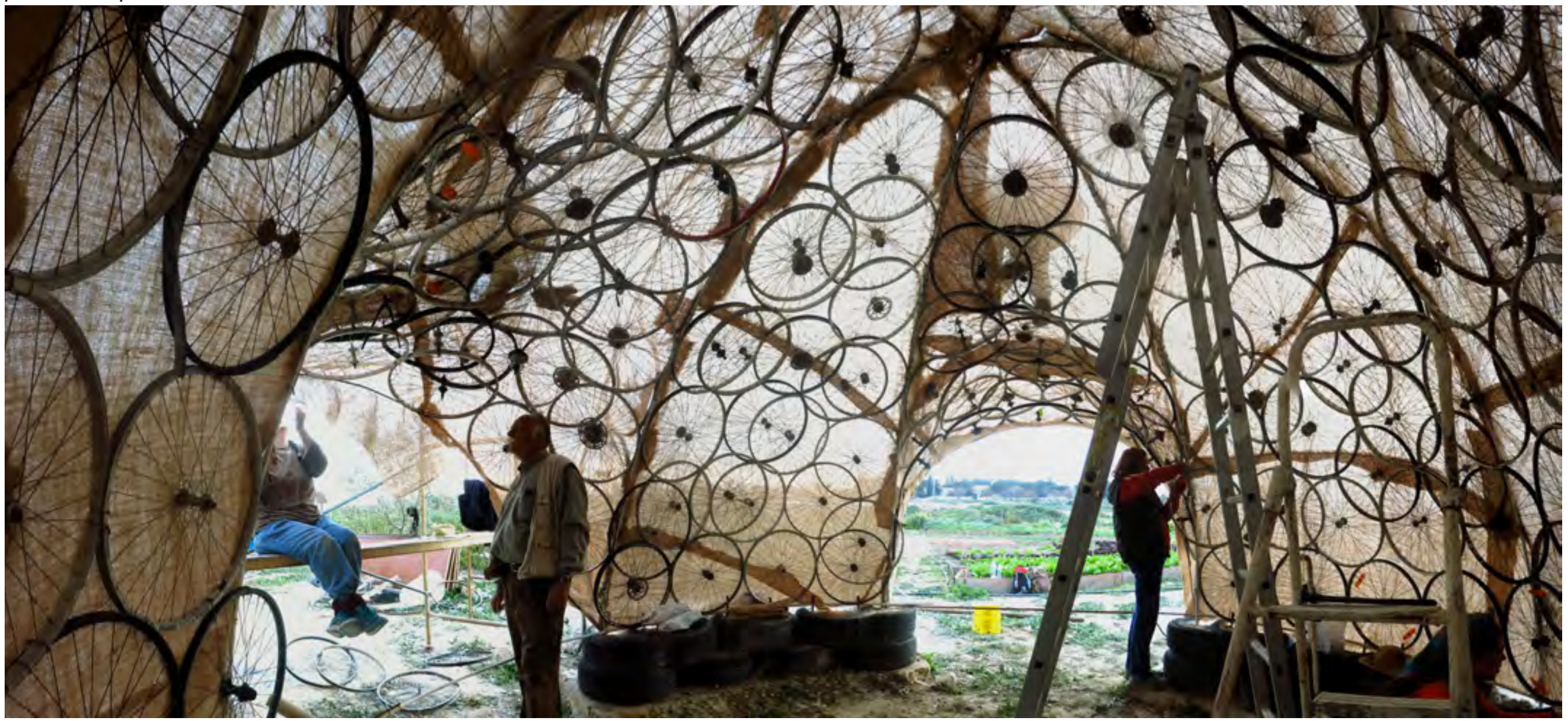


La niña y la especie de hamaca de llantas tejidas en el Jardín Botánico de Valencia.

No sólo estaba monisima la niña tumbada en esa especie de hamaca de llantas tejidas. También estaba cómoda. Tanto que se tiró un buen rato así, como flotando y cuando su padre la quitó, lloró. Pues claro. ¿Recordará de mayor ese extraño lugar con abundacia de especies vegetales, cartelitos de nombres científicos, artefactos de Ilantas de bicicleta y tejidos, laboratorios de residuos y

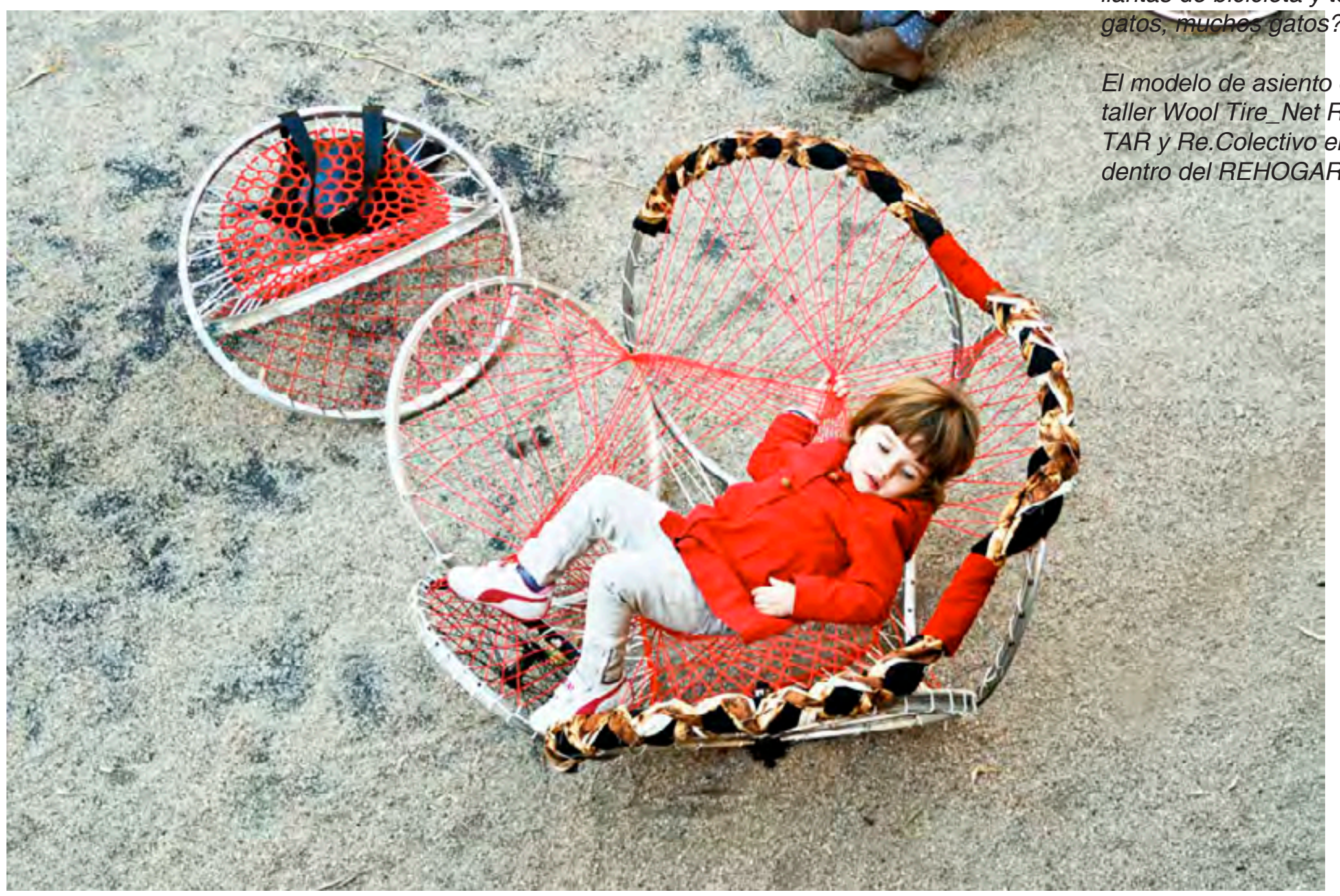




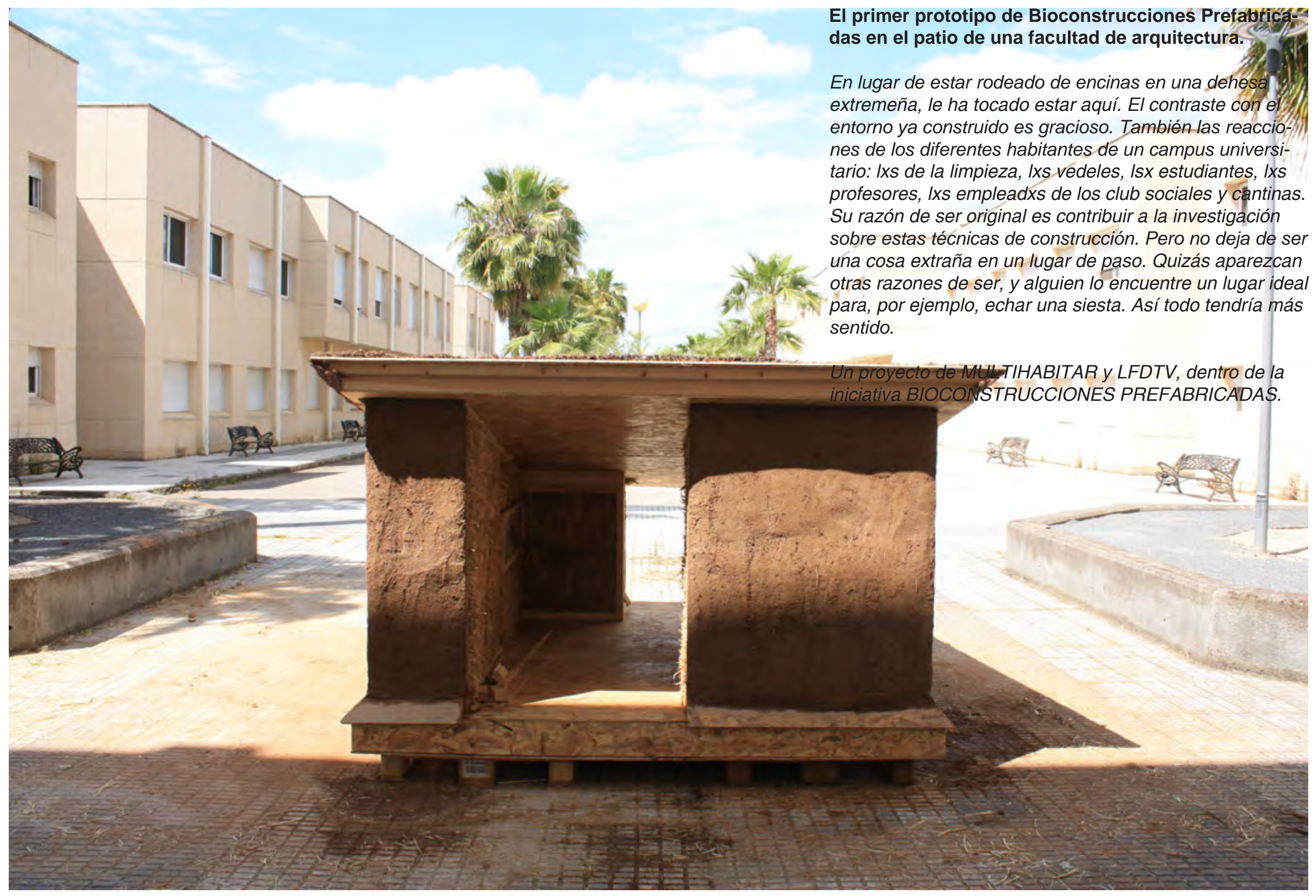

